\title{
Dynamic modeling of flow boiling within plate heat exchangers for heat pump and refrigeration applications
}

\section{Lennart Boese}

Frank Opferkuch
Julian Becker
Michael Wensing

\begin{abstract}
Brazed Plate Heat Exchangers (BPHEs) are increasingly used as evaporators for refrigeration and heat pump applications. Detailed understanding of the underlying heat transfer phenomena is required for their effective design and use. The number of correlations which are suitable for modeling the dynamics of flow boiling within BPHEs is rather low compared to other evaporator types. In this paper some correlations that involve integral values of steam quality are evaluated for different sets of experimental data from literature. Modifications to the correlations are presented, which allow to predict the quasi-local heat transfer coefficient in each refrigerant cell. The cells equal finite volumes that are composed to a dynamic model of a BPHE acting as evaporator. Heat transfer coefficient and heat flow rate from simulation results are compared to those calculated from existing experimental data based on the same boundary conditions. The fine-tuned evaporator model is finally used to demonstrate effects of sudden load changes for the evaporator performance.
\end{abstract}

\section{INTRODUCTION}

More flexible operation strategies of heat pumps, which support and stabilize the electrical grid, will increase the number of startup procedures and load cycles. More transient states of the heat pump cycle come along with thermo-hydraulic effects in the evaporator making the control of the process more difficult. Brazed Plate Heat Exchangers (BPHEs) offer compactness and high efficiency at low unit costs and are becoming increasingly important for refrigeration applications. Due to their complex structure of flow guidance with up to 5 main flow patterns (Vakili-Farahani, et al. 2016) that can occur during the evaporation, high heat transfer coefficients can be achieved, but the underlying transport phenomena are difficult to describe and model. By means of elaborate dynamic simulation models, the design and control of heat exchangers can be optimized for both transient and stationary operating points and inefficient states with high values of superheat avoided. Longo and Gasparella (2007) showed for three different refrigerants that a value of evaporator superheat of $10 \mathrm{~K}$ lead up to 30 to $40 \%$ reduction of the average heat transfer compared to when outlet vapor quality is around 0.8 .

\section{FLOW BOILING HEAT TRANSFER WITHIN PLATE HEAT EXCHANGERS}

Unlike other physical phenomena, nucleate boiling heat transfer, which occurs within BPHEs, can yet not be described mathematically on the basis of the prevailing mechanisms, even if initial progress has already been made in

Lennart Boese (lennart.boese@th-nuernberg.de) is research associate, Frank Opferkuch is professor and Julian Becker is student researcher at Technische Hochschule Nürnberg Georg Simon Ohm. Michael Wensing is professor at Friedrich-Alexander-Universität Erlangen-Nürnberg. 
this field (Dhir 2005). Until then, it is necessary to use empirical correlations, which provide estimations for the heat transfer coefficient (htc) as a function of thermodynamic state, variables that describe transport phenomena and other parameters. Correlations used by the manufacturers of BPHEs to describe heat transfer and pressure drop contain valuable empirical knowledge but are subject to secrecy and are unlikely to be published. Nevertheless, a considerable amount of correlations for evaporation in plate heat exchangers is available in the literature. In contrast to correlations for evaporation within other geometries, like tubes, there is still indistinction which of them will prove itself for larger amounts of evaporation data sets. A first approach is for example provided by Vakili-Farahani, et al. (2016), who apply correlations and measurement data crosswise and provide some statistical evaluation. However, the majority of the correlations and measurement provide only estimations of the average heat transfer coefficient, which can be used for calculation methods such as the Number of Transfer Units (NTU) or Log Mean Temperature Difference (LMTD). Eldeeb, et al. (2016) give a good overview of some of the most well-known correlations for evaporation and condensation in BPHEs.

$\bigcirc \triangle$ experimental data $=-$ Amalfi, et al. (2015) =-- Danilova, et al. (1981) =-- Donowski and Kandlikar (2000) =-- Han, et al. (2003)

(a)

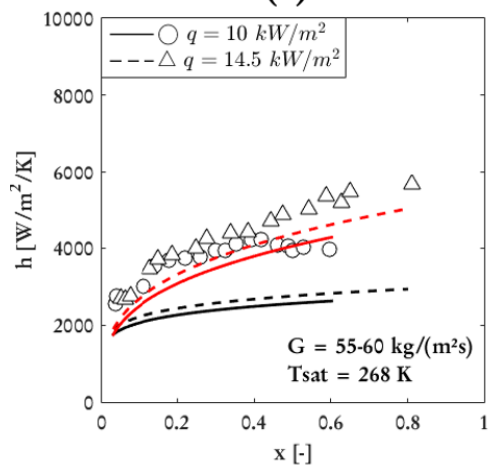

(d)

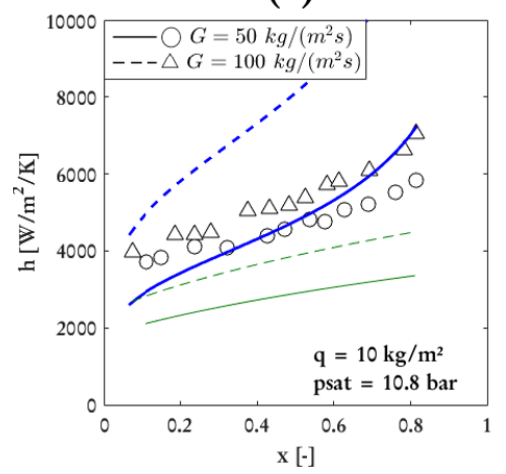

(b)

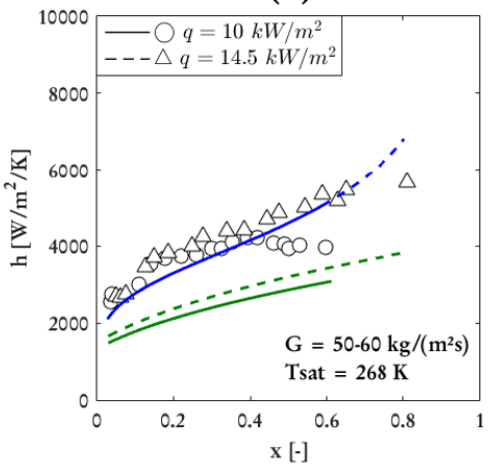

(e)

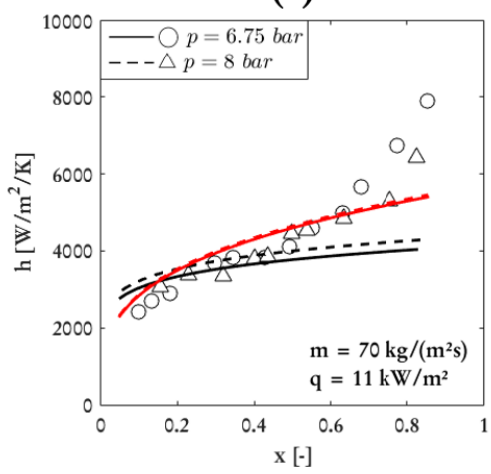

(c)

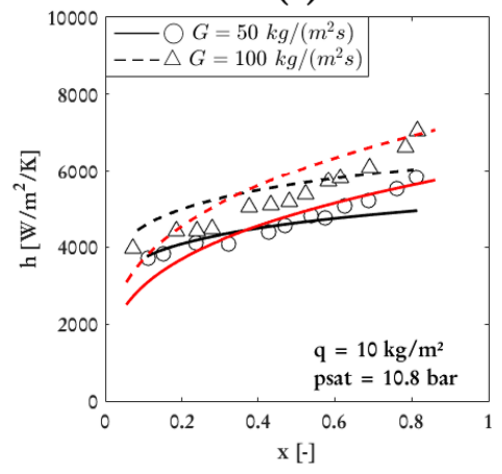

(f)

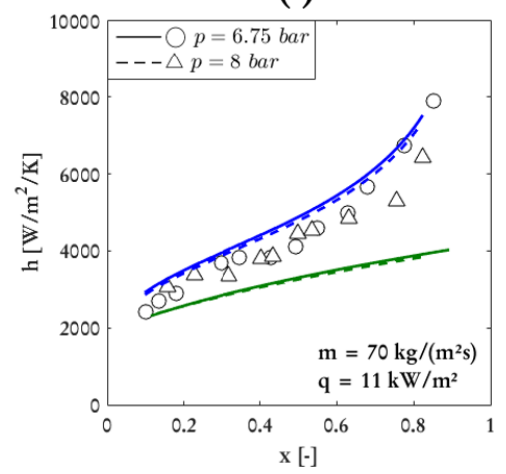

Figure 1 Comparison of correlations applied to experimental data from Djordjevic and Kabelac (2008) (a) and (b) for R134a, Hsieh and Lin (2002) (c) and (d) for R410A, Yan, et al. (1997) (e) and (f) for R134a.

\subsection{Heat transfer correlations and experimental observations}

Correlations developed for ammonia are not considered because of its significantly higher heat transfer 
coefficient compared to the hfc refrigerants analyzed in this study. For the dynamic modeling of flow boiling with lengthwise discretization, only correlations that directly or indirectly consider steam quality as a variable are considered. Of these, the correlations from Amalfi, et al. (2015), Donowski and Kandlikar (2000), Danilova, et al. (1981) and Han, et al. (2003) are evaluated in this study. A general correlation for nucleate boiling by Cooper (1984) will be used later for comparison purposes. The Cooper correlation is independent of steam quality but is reported to estimate BPHE average htc well when multiplied with a factor of 1.5 (Palm and Claesson 2006) or 1.7 (Huang 2010).

Different sets of measurement data allow calculating the heat transfer coefficient for chevron type plate heat exchangers for diverse geometries and boundary conditions. Figure 1 shows different correlations applied to segments of measurement data taken from authors where the input quantities for the correlations were available. The following conclusions and the depictured data represent the majority of more extensive data while there is a minority of data that lead to ambiguous or contradictory results. While other parameters are held constant, one can observe the following trends:

1. heat transfer coefficient increases with increasing heat flux, (a) and (b)

2. low mass flux tends correlate with low heat transfer coefficients, (c) and (d)

3. effect of the higher evaporation temperature in (f) compared to (e) is inconclusive and might be dependent on steam quality

Furthermore higher values of chevron angles (referring to vertical axis) increase both pressure drop and heat transfer coefficients. A general-purpose BPHE evaporator model and suitable correlations should reproduce these main observations. Subsequently, the Han, et al. (2003) correlation is discarded since it gives constantly too low values of heat transfer coefficient or was not correctly implemented. The Donowski and Kandlikar (2000) correlation developed on the basis on the data set from Yan, et al. (1997) for R134a. Thus validity for other refrigerants might not be given and its high a sensitivity to mass flux is noticeable. By contrast, the Amalfi, et al. (2015) correlation was developed from 1903 heat transfer data points for multiple refrigerants, geometries and refrigerants.

\subsection{Comparison and selection of applicable correlations for dynamic modeling}

For those correlations involving steam quality, it should be noted that steam is usually considered with its mean value. Steam quality is difficult to measure directly. In the experimental data used to develop the empirical correlations it is mostly calculated from energy balances. Eq. (1) gives the definition how steam quality will be calculated for a control volume with refrigerant in vapor-liquid equilibrium. It is further assumed that no slip between the velocities of refrigerant gas and liquid occurs. This means that flow steam quality, which is the relation of mass flow rate of gas phase to total mass flow rate, is equal to the local steam quality of the control volume.

$$
x=\frac{h-h_{l}}{h_{g}-h_{l}}
$$

While some experiments focused on single plates, in other experiments entire heat exchangers with a small number of plates were tested. Thus, the average of the steam quality used for calculating the average heat transfer coefficients may be based on a wide range of steam quality between inlet and outlet. New approaches are e.g. presented by Djordjevic and Kabelac (2008), where the quasi-local htc is derived from temperature readings inside the plate heat exchanger. The later presented simulation model of the heat exchanger divides the path of evaporating refrigerant into discrete cells. This requires prediction methods for the quasi-local heat transfer coefficient dependent of the time-varying steam quality of the cell. Since no such correlations for plate heat exchangers were found in the literature, the above correlations are used for this approach. Because of this an unknown amount of inaccuracy must 
be accepted and correlations may be used beyond their range of validity. This is encountered by the following piecewise definition of heat transfer coefficient dependent on local steam quality:

$$
\begin{gathered}
h_{t p}=\max \left(h_{s p}, h_{t p, c o r r}\right) \text { for } 0<\mathrm{x}<0.1 \\
h_{t p}=h_{t p, c o r r} \text { for } 0.1<\mathrm{x}<\mathrm{x}_{\mathrm{di}} \\
h_{t p}=h_{t p, c o r r}\left\{-\sin \left[\frac{2 \pi(x-1)}{\left(1-x_{d i}\right)}\right]\right\}+h_{s p}\left\{1+\sin \left[\frac{2 \pi(x-1)}{\left(1-x_{d i}\right)}\right]\right\} \text { for } \mathrm{x}_{\mathrm{di}}<\mathrm{x}<1
\end{gathered}
$$

Since the evaporation correlations do not map the heat transfer coefficients for single-phase fluid in the subcooled or superheated range, the correlation of Martin (2010) will be used in the later simulation for this range. The two-phase region of incipient evaporation with low steam quality might not be covered by some correlations or unrealistic low values of the heat transfer coefficient are returned. In this case the higher value of single-phase and two-phase heat transfer coefficients is used in the simulation model, see Eq. (2). This corresponds to the approach of Shah (1982) for the superposition of nucleate and convective boiling. However, it can be usually assumed that the refrigerant is in the two-phase state when leaving the expansion valve.

Wojtan, et al. (2005) present measurement data for the inception of dryout of refrigerant flow boiling in tubes. A strong decrease of heat transfer coefficient can be observed in the high quality region and the inception starting roughly between $\mathrm{x}=0.7$ and 0.9 . For the proposed modification of heat transfer coefficient this is effect is modeled by a transition between two-phase htc and single-phase htc by means of a sine function, see Eq. (4). For the later simulation transition is assumed to start at $\mathrm{x}_{\mathrm{di}}=0.8$. The Figure 2 (b) shows application of the methods to an exemplary curve of heat transfer coefficient over steam quality.

(a)

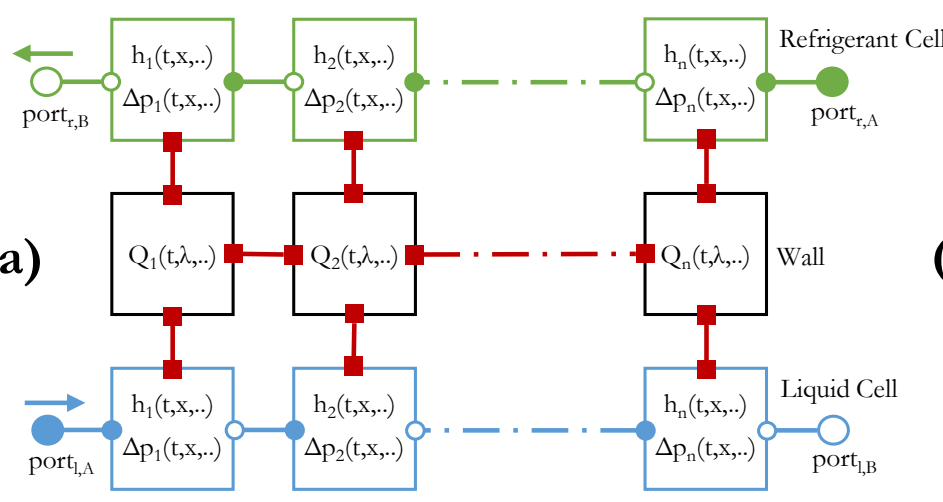

(b)

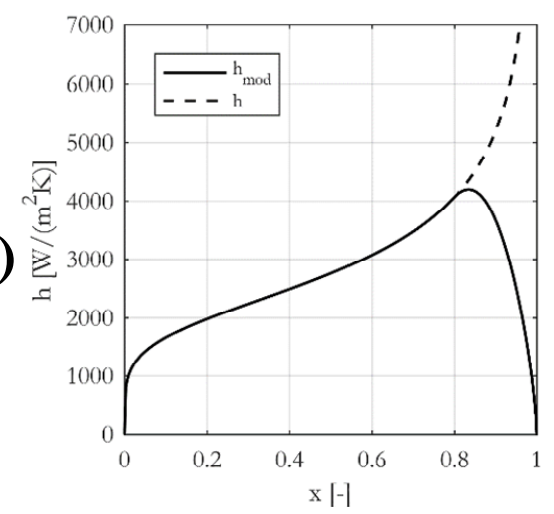

Figure 2 Structure of the heat exchanger model consisting of finite volume cells (a) and shape of heat transfer curve when modification is applied to Donowski and Kandlikar (2000) correlation (b).

\section{EVAPORATOR MODEL AND SINGLE-PHASE RESULTS}

The dynamic simulation model of the heat exchanger is programmed in the modeling language Modelica and taken from the component library TIL (Richter 2008; Schulze 2013) and slightly modified. The fluid channels are divided into $n$ discrete cells along its length (z-coordinate) following a 1D upwind discretization scheme. The fundamental modeling of refrigerant or liquid cells remains unchanged as well as the finite volume approach, by which these cells are composed together with heat transfer and pressure drop equations and geometrical parameters to a 
model of the heat exchanger. The energy balance, Eq. (5),for each refrigerant cell is formulated as the time derivative of specific enthalpy times cell mass which equals the sum of enthalpy streams entering/leaving the cell, heat flow and the time derivative of work by change in pressure. Two other fundamental equations come in addition: The continuity equation, Eq. (6), and momentum equation, Eq. (7), which is simplified by assuming the time derivative of the momentum and the difference between momentum at inlet and outlet to equal zero:

$$
\begin{gathered}
\frac{d h}{d t}=\frac{1}{M}\left[\dot{m}_{A}\left(h_{A}-h\right)+\dot{m}_{B}\left(h_{B}-h\right)+\dot{Q}+V \cdot \frac{d p}{d t}\right] \\
\dot{m}_{A}+\dot{m}_{B}=\left[\left(\frac{d \rho}{d h}\right)_{p} \frac{d h}{d t}+\left(\frac{d \rho}{d p}\right)_{h} \frac{d p}{d t}\right] A_{c h} \cdot l_{z} \\
p_{\mathrm{A}}-p_{B}=\Delta p
\end{gathered}
$$

The individual control volumes of the fluids and fluid wall are connected by equations in a bidirectional way, see Figure 2(a). Through object-oriented programming, the overall model of the heat exchanger can be easily integrated as a component for the later system simulation of a heat pump cycle.

Table 1. Geometrical Parameters of the modeled BPHE evaporator from Huang (2010)

\begin{tabular}{cccc}
\hline \hline Number of plates & $\mathrm{N}_{\mathrm{p}}=24$ & Overall heat transfer area & $\mathrm{A}=2.09 \mathrm{~m}^{2}$ \\
No. of refrigerant channels & $\mathrm{N}_{\mathrm{ch}, \mathrm{r}}=12$ & Port-to-port channel length & $\mathrm{L}_{\mathrm{p}}=519 \mathrm{~mm}$ \\
No. of water channels & $\mathrm{N}_{\mathrm{ch}, \mathrm{w}}=11$ & Effective channel length & $\mathrm{L}_{\mathrm{eff}}=466 \mathrm{~mm}$ \\
Channel width & $\mathrm{W}=180 \mathrm{~mm}$ & Corrugation depth & $\mathrm{b}=2 \mathrm{~mm}$ \\
Corrugation wavelength & $\lambda=8.1 \mathrm{~mm}$ & Enlargement factor & $\phi=1.14$ \\
Hydraulic diameter & $\mathrm{D}_{\mathrm{h}}=2 \mathrm{~b} / \phi=3.51 \mathrm{~mm}$ & Corrugation angle & $\beta=28^{\circ}$ or $60^{\circ}$ \\
\hline
\end{tabular}

Since in this study the accuracy of the heat transfer and the exact temperature profile was more important than a short simulation time, a high number of $\mathrm{N}=30$ cells was set for each primary, secondary fluid and wall. The fluid properties for each liquid or refrigerant cells are considered as integral values and are obtained from REFPROP (NIST 2015). Pressure losses on the secondary side are neglected and the effects of conduction and dispersion in the direction of fluid flow (z-coordinate) are ignored. The model BPHE consists of 24 chevron type plates in counterflow arrangement. The relevant geometrical parameter are given in Table 1.

\subsection{Single-Phase Heat Transfer Modeling}

The modeling approach using the finite volume method is validated with single-phase heat transfer data from Huang (2010). Two correlations are used. The first correlation for the Nusselt number is based on a widespread approach using Reynolds to account for turbulence of flow and Prandtl number for the ratio of momentum diffusivity to thermal diffusivity. The exponent $\mathrm{m}$ and the factor $\mathrm{C}_{1}$ are fitted to the measurement data:

$$
N u_{s p}=C_{1} \cdot \operatorname{Re}^{m} \cdot \operatorname{Pr}^{0.33}\left(\frac{\mu}{\mu_{\text {wall }}}\right)^{0.17}
$$

Correlation and fitting factors are taken from Huang (2010) and were obtained by fitting the correlation to data for the heating of cold water with the same BPHE which will later be used as evaporator. As an alternative approach, the correlation of Martin (2010) was implemented, which is also used for modeling the heating of subcooled liquid or 
superheated steam. As expected, the results from experiment and simulation show good agreement for the correlation of Huang (2010) with a mean absolute error $|\delta|=0.67 \%$ for the cold side and $|\delta|=2.79 \%$ for the hot side. The unfitted correlation from Martin (2010) results in significantly higher deviations.

Table 3. Experimental conditions from Huang (2010) for water to water heat transfer

\begin{tabular}{cccccc}
\hline Chevron angle & No. of data points & $\mathbf{R e}_{\mathbf{h}}$ & $\mathbf{T}_{\mathbf{h}, \text { in }}\left[{ }^{\mathbf{}} \mathbf{C}\right]$ & $\mathbf{R e}_{\mathbf{c}}$ & $\mathbf{T}_{\mathbf{c}, \text { in }}\left[{ }^{\circ} \mathbf{C}\right]$ \\
\hline \hline 28 & 22 & $510-560$ & $55.0-56.0$ & $280-1100$ & $18.4-19.3$ \\
60 & 16 & $430-460$ & $56.0-56.5$ & $350-1030$ & $18.3-19.1$ \\
\hline
\end{tabular}

\subsection{Two-Phase Heat Transfer Modeling}

For modeling the fluid flow on the side of the refrigerant (primary side), the following assumptions are additionally made. The influence of oil can significantly lower the heat transfer at high admixture (Spindler and Hahne 2009). In the following, it is neglected because it is unknown whether its influence is contained in experimental data sets or the correlations based upon them. Since measurement data are usually obtained under laboratory conditions, the influence of fouling is also neglected. The presented modified correlations for two-phase region are concatenated with the correlation of Martin (2010) that is used for the single-phase heat transfer. In the transition area around $x=0$ and $\mathrm{x}=1$, the smooth transition function from TIL is used to improve the numerical stability of the simulation. The pressure losses on the refrigerant side are modeled as follows:

$$
\Delta p=\Delta p_{p}+\Delta p_{f r i}+\Delta p_{s t a}
$$

Pressure drops caused by the acceleration of the fluid during evaporation are neglected in a first approximation being comparatively low according to results from Amalfi (2016). The pressure loss at each inlet or outlet port is calculated according to Shah and Focke (1988):

$$
\Delta p_{p}=0.75 \cdot N_{p a s s} \cdot \frac{G_{p}^{2}}{2 \cdot \rho}
$$

For modeling the friction pressure loss within the refrigerant channels the correlation of Amalfi, et al. (2015) is used. Maldistribution of refrigerant between the channels is not considered. Table 3 gives an overview of the boundary conditions of the evaluated experimental data. The complete measurement data sets for inlet temperature, volume flow and inlet pressure can be found at Huang (2010).

Table 3. Experimental conditions from Huang (2010)

\begin{tabular}{cccccccc}
\hline Refrigerant & $\begin{array}{c}\text { Chevron } \\
\text { angle }\end{array}$ & $\begin{array}{c}\text { No. of data } \\
\text { points }\end{array}$ & $\begin{array}{c}\mathbf{G}_{\mathbf{z}, \mathbf{w}} \\
{\left[\mathbf{k g} /\left(\mathbf{m}^{2} \mathbf{s}\right)\right]}\end{array}$ & $\begin{array}{c}\mathbf{T}_{\mathbf{w}, \text { in }} \\
{\left[{ }^{\circ} \mathbf{C}\right]}\end{array}$ & $\begin{array}{c}\mathbf{G}_{\mathbf{z}, \mathbf{r}} \\
{\left[\mathbf{k g} /\left(\mathbf{m}^{2} \mathbf{s}\right)\right]}\end{array}$ & $\begin{array}{c}\mathbf{T}_{\text {sat }} \\
{\left[{ }^{\circ} \mathbf{C}\right]}\end{array}$ & $\begin{array}{c}\mathbf{q} \\
{\left[\mathbf{k W} / \mathbf{m}^{2}\right]}\end{array}$ \\
\hline \hline \multirow{2}{*}{$\mathrm{R} 134 a$} & 28 & 58 & $125-203$ & $13.7-16.0$ & $5.6-30.3$ & $5.9-12.2$ & $1.9-6.1$ \\
& 60 & 59 & $124-203$ & $13.8-15.9$ & $5.8-27.0$ & $7.8-10.6$ & $3.8-6.4$ \\
\multirow{2}{*}{ R507A } & 28 & 22 & $200-204$ & $16.3-16.6$ & $16-0-29.8$ & $7.8-10.6$ & $3.8-6.4$ \\
& 60 & 11 & $202-203$ & $16.2-16.3$ & $17.6-31.4$ & $9.2-12.6$ & $4.7-6.9$ \\
\hline
\end{tabular}

\section{RESULTS AND DISCUSSION}

Figure 3 displays a parity plot, comparing simulated and experimental heat transfer coefficients and heat flow in the case of refrigerant R134a and $\beta=28^{\circ}$. In addition to the correlations outlined above, the Huang (2010) correlation fitted to the measurement data is displayed. As expected, it shows a good match. 
The results for the other data points are presented in Table 4. The modified Danilova, et al. (1981) (B) correlation shows the lowest overall deviation for the evaluated experimental data. The modified Cooper (1984) correlation (D) predicts the htc for R134a well but shows great deviations for R507A. The modified Amalfi, et al. (2015) (A) and Donowski and Kandlikar (2000) (C) have moderate prediction quality for the specific data evaluated.
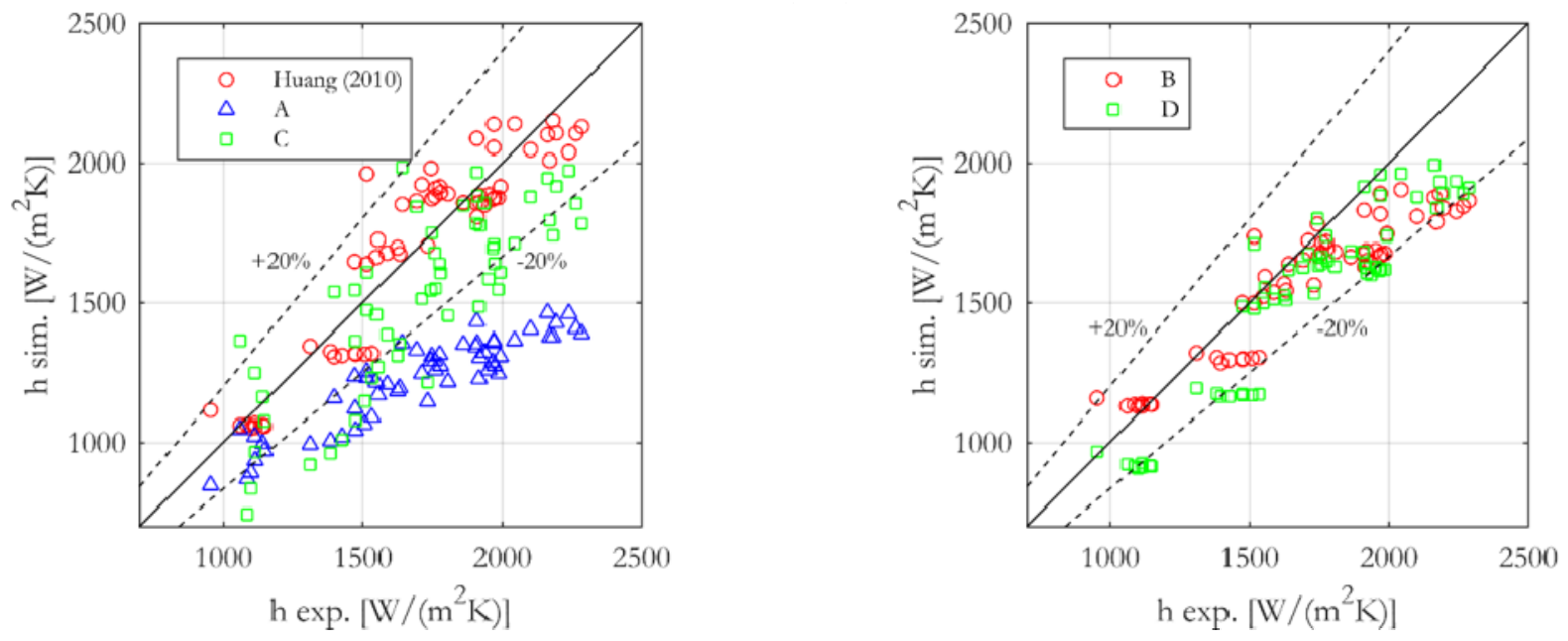

Figure 3 Comparison of experimental and simulated two-phase htc for flow boiling of R134a and chevron angle $\beta=28^{\circ}$.

The experimental values of Huang (2010) were determined using the logarithmic mean temperature difference. The fluid properties used in his calculations were from ASHRAE Handbook 2005 at saturation temperature. Huang (2010) indicates an uncertainty of 7.6-8.6\% for his calculated htc. According to Claesson (2005) the LMTD approach has to be modified when applied to a BPHE evaporator where htc is not constant along its length.

Table 4. Mean error $\delta$ and mean absolute error $|\delta|$ between correlation and simulation

\begin{tabular}{|c|c|c|c|c|c|c|}
\hline Refrigerant & Chevron angle & Huang (2010) & $\mathbf{A}$ & B & $\mathrm{C}$ & D \\
\hline \multirow{4}{*}{$\mathrm{R} 134 \mathrm{a}$} & \multirow{2}{*}{28} & $|\delta|=6.9 \%$ & $|\delta|=26.7 \%$ & $|\overline{|c|} \delta|=8.5 \%$ & $|\delta|=14.7 \%$ & $|\delta|=11.2 \%$ \\
\hline & & $\delta=0.6 \%$ & $\delta=-26.7 \%$ & $\delta=-6.4 \%$ & $\delta=-11.4 \%$ & $\delta=-10.6 \%$ \\
\hline & \multirow{2}{*}{60} & $|\delta|=11.4 \%$ & $|\delta|=11.4 \%$ & $|\delta|=15 \%$ & $|\delta|=20.5 \%$ & $|\delta|=16.4 \%$ \\
\hline & & $\delta=-10.9 \%$ & $\delta=-10.9 \%$ & $\delta=-14.9 \%$ & $\delta=-20.2 \%$ & $\delta=-16.3 \%$ \\
\hline \multirow{4}{*}{ R507A } & \multirow{2}{*}{28} & $|\delta|=13.6 \%$ & $|\delta|=18.0 \%$ & $|\delta|=20.6 \%$ & $|\delta|=11.9 \%$ & $|\delta|=74.3 \%$ \\
\hline & & $\delta=3.5 \%$ & $\delta=14.2 \%$ & $\delta=17.3 \%$ & $\delta=4.9 \%$ & $\delta=74.3 \%$ \\
\hline & \multirow[t]{2}{*}{60} & $|\delta|=12.9 \%$ & $|\delta|=26.3 \%$ & $|\delta|=14.6 \%$ & $|\delta|=12.7 \%$ & $|\delta|=56.4 \%$ \\
\hline & & $\delta=-7.6 \%$ & $\delta=19.86 \%$ & $\delta=2.2 \%$ & $\delta=-9.2 \%$ & $\delta=53.3 \%$ \\
\hline \multicolumn{2}{|c|}{ Overall } & $|\delta|=10.1 \%$ & $|\delta|=19.4 \%$ & $|\delta|=13.3 \%$ & $|\delta|=16.4 \%$ & $|\delta|=25.8 \%$ \\
\hline
\end{tabular}

\subsection{Dynamic Response of the Evaporator}

Figure 4 shows the step response of the evaporator using the modified Danilova, et al. (1981) correlation. During the transient state change, the maxima of steam quality $\mathrm{x}$ and quasi-local heat transfer coefficient $\mathrm{h}$ move in the direction of refrigerant inlet. While the superheat at outlet $\mathrm{SH}$ increases from 5 to $10 \mathrm{~K}$, the average heat transfer coefficient is reduced by $30.6 \%$. The presented model can be utilized for different purposes. Maintaining a high number of cells and fitting the model to experimental data, evaporation transients can be further identified by 
implementing those thermo-hydraulic effects in the model that were neglected so far. By reducing the number of cells or switching to a moving boundary approach, simulation can be performed in real time and act as feedback for the control of refrigerant mass flow.
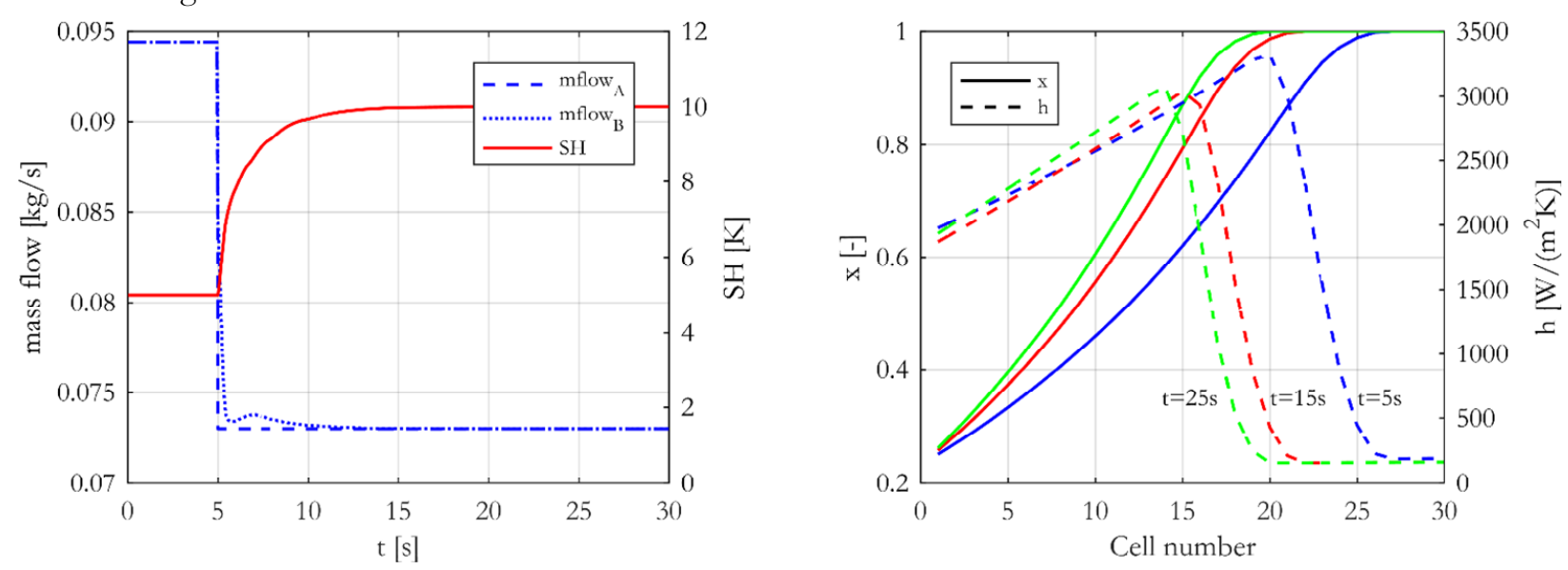

Figure 4 Step response of the evaporator after an instantaneous drop in mass flow by $23 \%$.

\section{CONCLUSION}

Available correlations for flow boiling in BPHEs considering steam quality are comparatively evaluated on the basis of experimental data. After mathematical modifications and by concatenating single and two-phase correlations a quasi-local heat transfer coefficient for a lengthwise discretization scheme can be reproduced. The prediction method based on the Danilova, et al. (1981) correlation shows the best accordance with a given set of experimental boiling data from literature. Implementing this prediction method into a dynamic simulation model of a BPHE evaporator, the response to a step reduction in refrigerant mass flow can be demonstrated. The increase of superheat zone and reduction of average heat transfer coefficient follows the trends reported by Longo and Gasparella (2007) from experimental results. However, more experimental work is required to verify the modeling method and to evaluate suitable correlations for heat transfer of superheated refrigerants in BPHEs. Nevertheless, the presented approach can contribute to describe the dynamic behavior of heat pump cycles and be utilized for novel control strategies.

\section{NOMENCLATURE}

\begin{tabular}{|c|c|c|c|c|c|c|}
\hline$G$ & mass flux $\left(\mathrm{kg} / \mathrm{m}^{2} \mathrm{~s}\right)$ & $b$ & heat transfer coefficient (W) & K) o & spec & ic enthalpy (J/kg) \\
\hline$l$ & length (m) & $M$ & mass of control volume & $\dot{m}$ & $=$ & mass flow $(\mathrm{kg} / \mathrm{s})$ \\
\hline$N_{\text {pass }}=$ & number of passes in BPHE & $p$ & pressure $(\mathrm{Pa})$ & $\dot{Q}$ & $=$ & heat flow rate (W) \\
\hline$=$ & density $\left(\mathrm{kg} / \mathrm{m}^{3}\right)$ & $V$ & volume of control volume & $x$ & $=$ & vapor quality \\
\hline
\end{tabular}

\section{Subscripts}

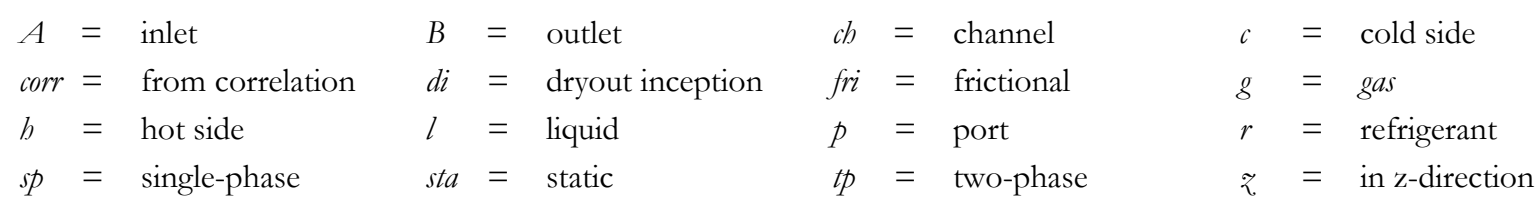




\section{REFERENCES}

Amalfi, R. L., F. Vakili-Farahani and J. R. Thome. 2015. Flow boiling and frictional pressure gradients in plate heat exchangers. Part 2: Comparison of literature methods to database and new prediction methods. International Journal of Refrigeration 65:185-203. DOI:10.1016/j.ijrefrig.2015.07.009

Amalfi, R. L. 2016. Two-Phase Heat Transfer Mechanisms Within Plate Heat Exchangers: Experiments, Modeling and Simulations. Doctoral dissertation. EPFL. DOI:10.5075/epfl-thesis-6856

Claesson, J. 2005. Correction of logarithmic mean temperature difference in a compact brazed plate evaporator assuming heat flux governed flow boiling heat transfer coefficient. International Journal of Refrigeration 28(4): 573-578. DOI:10.1016/j.ijrefrig.2004.09.011.

Cooper, M.G. 1984. Heat flow rates in saturated nucleate pool boiling - A wide-ranging examination using reduced properties. Adv. Heat Transfer 16:157-239. DOI: 10.1016/S0065-2717(08)70205-3

Danilova, G.N., V.M. Azarskov and B.B. Zemskov. 1981 Teploobmen V Plastinchatihispariteljan Razichnole Geometri - Heat Transfer in Plate Evaporators of Different Geometry. Kholod. Tek. 4: 25-31.

Dhir, V. K. Mechanistic Prediction of Nucleate Boiling Heat Transfer-Achievable or a Hopeless Task?. 2005. ASME J. Heat Transfer 128(1):1-12. DOI:10.1115/1.2136366.

Djordjevic, E. and S. Kabelac. 2008. Flow boiling of R134a and ammonia in a plate heat exchanger. International Journal of Heat and Mass Transfer 51(25-26):6235-6242. DOI:10.1016/j.ijheatmasstransfer.2008.01.042.

Donowski, V.D. and S. G. Kandlikar. 2000. Correlating evaporation heat transfer coefficient of refrigerant R-134a in a plate heat exchanger. Engineering Foundation Conference on Pool and Flow Boiling, Alaska.

Eldeeb, R., V. Aute and R. Radermacher. 2016. A survey of correlations for heat transfer and pressure drop for evaporation and condensation in plate heat exchangers. International Journal of Refrigeration 65: 12-26. DOI:10.1016/j.ijrefrig.2015.11.013.

Han, D. H., Lee, K. J. and Kim, Y. H. 2003. Experiments on the characteristics of evaporation of R410A in brazed plate heat exchangers with different geometric configurations. Appl. Therm. Eng. 23(10):1209-1225. DOI: 10.1016/S1359-4311(03)00061-9

Huang, J. 2010. Performance analysis of plate heat exchangers used as refrigerant evaporators. Doctoral dissertation.

Hsieh, Y. Y. and T. F. Lin. 2002. Saturated flow boiling beat transfer and pressure drop of refrigerant R-410 A in a vertical plate heat exchanger. International Journal of Heat and Mass Transfer 45(5): 1033-1044. DOI:10.1016/S0017-9310(01)00219-8.

Longo, G.A. and A. Gasparella. 2007. Heat transfer and pressure drop during HFC refrigerant vaporisation inside a brazed plate heat exchanger. International Journal of Heat and Mass Transfer 50: 5194-5203. DOI:10.1016/j.ijheatmasstransfer.2007.07.001.

Martin, H. 2010. N6 Pressure Drop and Heat Transfer in Plate Heat Exchangers. In: VDI e. V. VDI Heat Atlas. Springer. Berlin, Heidelberg.

NIST. 2015. NIST Reference Fluid Thermodynamic and Transport Properties Database (REFPROP): Version 9.1.

Palm, B. and J. Claesson, 2006. Plate heat exchangers: Calculation methods for single and two-phase flow. Heat Transfer Eng. 27(4): 88-98.

Richter, C. 2008. Proposal of New Object-Oriented Equation-Based Model Libraries for Thermodynamic Systems. Doctoral dissertation. Technische Universitaet Braunschweig.

Vakili-Farahani, F., R. L. Amalfi and J. R. Thome. 2016. Two-Phase Heat Transfer and Pressure Drop within Plate Heat Exchangers. In J. R. Thome Encyclopedia of two-phase heat transfer and flow. New Jersey: World Scientific.

Schulze, C. 2013. A Contribution to Numerically Efficient Modelling of Thermodynamic Systems. Doctoral dissertation. Technische Universitaet Braunschweig.

Shah, M. M. 1982. Chart correlation for saturated boiling heat transfer: equations and further study. ASHRAE Trans 88: 185-196.

Shah, R. K. and W. W. Focke. 1988. Plate Heat Exchangers and Their Design Theory. In Heat Transfer Equipment Design. Washington, DC: Hemisphere Publishing.

Spindler, K. and E. Hahne. 2009. The influence of oil on nucleate boiling heat transfer. Heat Mass Transfer 45: 979-990.

Wojtan, L., T. Ursenbacher and J. R. Thome. 2005. Investigation of flow boiling in horizontal tubes: Part II-Development of a new beat transfer model for stratified-wavy, dryout and mist flow regimes. International Journal of Heat and Mass Transfer 48(14): 29702985. DOI:10.1016/j.ijheatmasstransfer.2004.12.013.

Yan, Y., T. Lin and B. Yang. 1997. Evaporation Heat Transfer and Pressure Drop of Refrigerant R134a in a Plate Heat Exchanger. ASME Turbo Expo: Power for Land, Sea, and Air, ASME 1997 Turbo Asia Conference. DOI:10.1115/97-AA-048. 